\title{
The Efficacy and Safety of Long-term Pirfenidone Therapy in Patients with Idiopathic Pulmonary Fibrosis
}

\author{
Kazumasa Ogawa ${ }^{1}$, Atsushi Miyamoto ${ }^{1}$, Shigeo Hanada ${ }^{1}$, Yui Takahashi ${ }^{1}$, Kyoko Murase ${ }^{1}$, \\ Sayaka Mochizuki ${ }^{1}$, Hironori Uruga ${ }^{1}$, Hisashi Takaya ${ }^{1}$, Nasa Morokawa ${ }^{1}$ and Kazuma Kishi ${ }^{1,2}$
}

\begin{abstract}
:
Objective Pirfenidone (PFD) is often used for years, but the efficacy and safety of long-term PFD therapy in patients with idiopathic pulmonary fibrosis (IPF) are not fully understood.

Methods and Patients We retrospectively evaluated 46 patients with IPF who received PFD between February 2009 and August 2014. The efficacy and safety of PFD therapy were compared between 2 groups: long-term therapy patients who received PFD for over 1 year (group $\mathrm{L}, \mathrm{n}=30,65 \%$ ) and short-term therapy patients who could not receive PFD for more than 1 year due to worsening of their condition or side effects (group $\mathrm{S}, \mathrm{n}=16,35 \%$ ).

Results The median age of the 46 patients was 70.5 years, and the median baseline $\%$ predicted forced vital capacity (\%FVC) was $70.0 \%$. The changes in the FVC in group $\mathrm{L}$ were $-120 \mathrm{~mL}$ and $-170 \mathrm{~mL}$ at 12 and 24 months after receiving PFD, respectively. The respective median survival times after PFD therapy in groups $\mathrm{L}$ and $\mathrm{S}$ were 1,612 days and 285 days $(\mathrm{p}<0.001)$. The patients in group $\mathrm{L}$ experienced a longer time free of acute exacerbation of IPF than those in group S (947 days vs. 145 days, $\mathrm{p}=0.001$ ). A multivariate analysis revealed that $\% \mathrm{FVC}<60 \%$ was a predictor of the inability to receive PFD for over 1 year (odds ratio $0.240,95 \%$ confidence interval $0.060-0.958 ; \mathrm{p}=0.043$ ). With regard to grade $3-5$ adverse events, only one patient exhibited grade 3 hyponatremia.
\end{abstract}

Conclusion Long-term PFD therapy is effective, with few severe adverse events.

Key words: acute exacerbation, idiopathic pulmonary fibrosis, interstitial pneumonia, long-term effects, pirfenidone

(Intern Med 57: 2813-2818, 2018)

(DOI: 10.2169/internalmedicine.0559-17)

\section{Introduction}

Idiopathic pulmonary fibrosis (IPF) is a specific form of chronic progressive fibrosing interstitial pneumonia (IP) of unknown cause (1). It is the most frequent type of IP and the one with the poorest prognosis. Pirfenidone (PFD) is an antifibrotic drug and was first approved in Japan in 2008. PFD is now used in patients with IPF in many countries, following the completion of several clinical studies (2-4). PFD is often prescribed for years $(5,6)$. The safety of longterm PFD therapy was reported in the extension study of a phase III trial. However, the efficacy of long-term PFD ther- apy in real-world practice has not been adequately assessed (7).

In this study, we investigated the clinical characteristics of patients with IPF who were able to take PFD for over 1 year (long-term) and those who were unable to take it for that long in an effort to identify factors related to the capacity to tolerate long-term PFD therapy.

\section{Materials and Methods}

We retrieved the records of 106 patients who took PFD between February 2009 and August 2014 at Toranomon Hospital in Tokyo, Japan. Fifty-four were excluded: 26 be-

${ }^{1}$ Department of Respiratory Medicine, Respiratory Center, Toranomon Hospital, Japan and ${ }^{2}$ Okinaka Memorial Institute for Medical Research, Japan

Received: November 20, 2017; Accepted: February 19, 2018; Advance Publication by J-STAGE: May 18, 2018

Correspondence to Dr. Kazumasa Ogawa, kaz_sap_tok@yahoo.co.jp 
Table 1. Characteristics of the Study Patients.

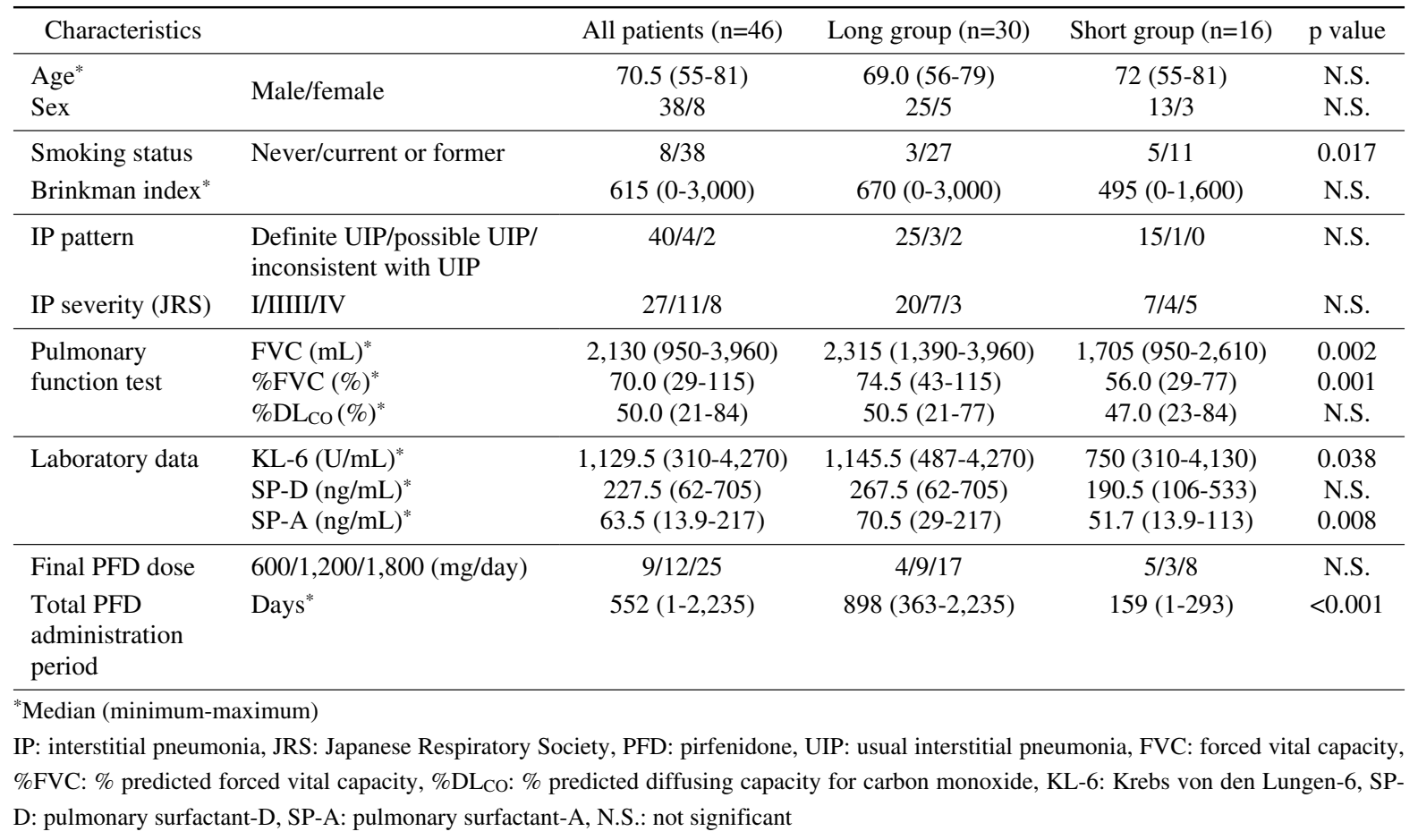

cause their laboratory data and medical charts were not available, as they had started PFD at other hospitals, and 28 because we could not correctly assess whether or not they had taken PFD for over 1 year, as we did not follow them up after 1 year. Of the remaining 52 patients, 46 had IPF. The medical charts, laboratory data, pulmonary function test results, chest radiography findings, and high-resolution computed tomography (HRCT) findings of these 46 patients were reviewed. We also retrospectively compared the clinical characteristics, efficacy, and safety associated with PFD therapy in those who received PFD for over 1 year (longterm PFD therapy; group $\mathrm{L}, \mathrm{n}=30,65 \%$ ) and those who were unable to take PFD for more than 1 year due to worsening of their condition or associated side effects (short-term PFD therapy; group $\mathrm{S}, \mathrm{n}=16,35 \%)$. The Brinkman index was calculated as the number of cigarettes per dayxthe number of smoking years.

The diagnosis of IP was made based on the official statement of the American Thoracic Society (ATS)/European Respiratory Society (ERS)/Japanese Respiratory Society (JRS)/Latin American Thoracic Association (ALAT) (1). IP HRCT patterns were assessed by a thoracic radiologist and two pulmonologists independently, and final diagnoses were made by a consensus. The severity of IPF was determined by the Japanese guideline. In accordance with this guideline, patients were classified as stage I if their resting arterial partial pressure of oxygen $\left(\mathrm{PaO}_{2}\right)$ was $\geq 80$ Torr, stage II if it was $\geq 70$ Torr and $<80$ Torr, stage III if it was $\geq 60$ Torr and $<70$ Torr, and stage IV if it was $<60$ Torr. The severities of stages II and III were adjusted to stages III and IV, respectively, if the peripheral capillary oxygen saturation $\left(\mathrm{SpO}_{2}\right)$ was $<90 \%$ during the 6-minute walk test $(3,5)$.
Acute exacerbation of IP was diagnosed using the definition proposed by Collard et al. (8), which requires all of the following conditions to be fulfilled: 1) a previous or concurrent diagnosis of IPF; 2) acute worsening or development of dyspnea, typically $<1$ month in duration; 3) computed tomography findings showing new bilateral ground-glass opacity and/or consolidation superimposed on a background pattern consistent with a usual interstitial pneumonia (UIP) pattern; and 4) deterioration of the condition not fully explained by cardiac failure or fluid overload. Adverse events were enumerated based on the Common Terminology Criteria for Adverse Events ver. 4.0.

Statistical analyses were performed using the Statistical Package for the Social Sciences (SPSS) software program (version 23.0; SPSS, Chicago, USA). Comparisons of the characteristics of patients in groups $\mathrm{L}$ and $\mathrm{S}$ were performed with the Mann-Whitney U test, Wilcoxon's signed rank test, and chi-squared test as appropriate. A logistic regression analysis was conducted for univariate and multivariate analyses of risk factors associated with being in group $\mathrm{S}$. The survival time was analyzed with the Kaplan-Meier method and compared between groups $\mathrm{L}$ and $\mathrm{S}$ with the $\log$ rank test. Statistical significance was defined as $\mathrm{p}<0.05$.

This study was approved by the institutional review board of Toranomon Hospital (No. 1167).

\section{Results}

The characteristics of all 46 patients are shown in Table 1 . Their median age was 70.5 (55-81) years; 38 patients were men, and 8 were women. The IP HRCT patterns were definite UIP in 40 patients (87\%), possible UIP in $4(9 \%)$, 
Table 2. Changes in Forced Vital Capacity.

\begin{tabular}{|c|c|c|c|c|}
\hline Variables & & Long group $(\mathrm{n}=30)$ & Short group $(\mathrm{n}=16)$ & $\mathrm{p}$ value \\
\hline$\Delta \mathrm{FVC}$ (12 months before PFD therapy) & Median (range) $(\mathrm{mL})$ & $-300(-1,320$ to 110$)$ & $-390(-640$ to -50$)$ & N.S. \\
\hline$\Delta$ FVC (6 months before PFD therapy) & Median (range) $(\mathrm{mL})$ & $-190(-1,000$ to 130$)$ & $-340(-480$ to -30$)$ & N.S. \\
\hline$\Delta \mathrm{FVC}$ (6 months after PFD therapy) & Median (range) $(\mathrm{mL})$ & $-30(-550$ to 660$)$ & $-30(-400$ to 280$)$ & N.S. \\
\hline$\Delta \mathrm{FVC}$ (12 months after PFD therapy) & Median (range) $(\mathrm{mL})$ & $-120(-530$ to 560$)$ & N.E. & - \\
\hline$\Delta$ FVC (24 months after PFD therapy) & Median (range) $(\mathrm{mL})$ & $-170(-600$ to 580$)$ & N.E. & - \\
\hline$\Delta \% \mathrm{FVC}$ (12 months before PFD therapy) & Median (range) (\%) & $-9(-31.8$ to 5$)$ & $-12(-21$ to 0$)$ & N.S. \\
\hline$\Delta \% \mathrm{FVC}$ (6 months before PFD therapy) & Median (range) $(\%)$ & $-3(-29$ to 5$)$ & $-7(-13$ to -7$)$ & N.S. \\
\hline$\Delta \%$ FVC (6 months after PFD therapy) & Median (range) $(\%)$ & $0(-14.9$ to 10$)$ & $-2(-11$ to 7$)$ & N.S. \\
\hline$\Delta \% \mathrm{FVC}$ (12 months after PFD therapy) & Median (range) $(\%)$ & $-3.1(-16$ to 17$)$ & N.E. & - \\
\hline$\Delta \% \mathrm{FVC}$ (24 months after PFD therapy) & Median (range) $(\%)$ & $-6(-18$ to 18$)$ & N.E. & - \\
\hline
\end{tabular}

$\Delta$ : changes in, FVC: forced vital capacity, \%FVC: \% predicted forced vital capacity, SD: standard deviation, N.E.: not examined, N.S.: not significant

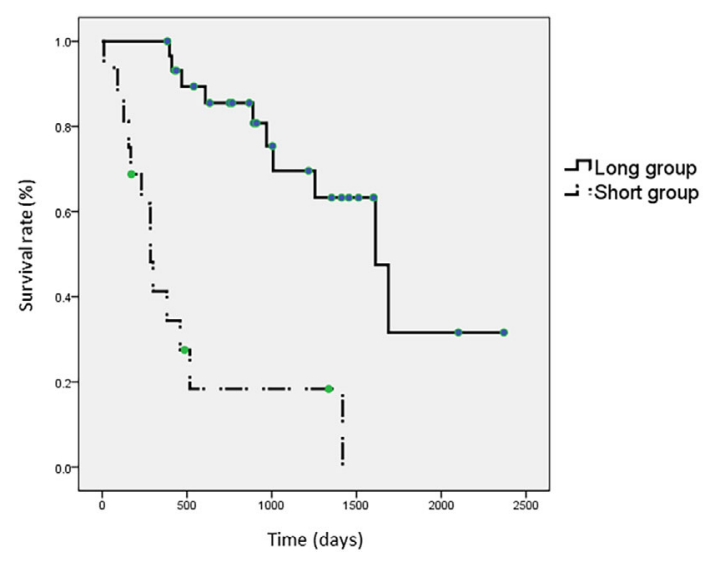

Figure 1. The patient survival by the duration of pirfenidone therapy. The long-term pirfenidone group exhibited a significantly longer median survival time than the short-term pirfenidone group (1,612 days vs. 285 days, $p<0.001)$.

and inconsistent with UIP in 2 (4\%). There were more smokers in group $\mathrm{L}$ than in group $\mathrm{S}$. The median forced vital capacity (FVC) at the time of taking PFD was better in group $\mathrm{L}$ than in group $\mathrm{S}(2,315 \mathrm{~mL}$ vs. $1,705 \mathrm{~mL}, \mathrm{p}=0.002)$, and the median baseline $\%$ predicted FVC (\% FVC) was also better in group L than in group $\mathrm{S}(74.5 \%$ vs. $56.0 \%$, $\mathrm{p}=$ 0.001). In group $\mathrm{L}$, the median Krebs von den Lungen-6 (KL-6) level was $1,145.5 \mathrm{U} / \mathrm{mL}$, and the median pulmonary surfactant-A (SP-A) level was $70.5 \mathrm{ng} / \mathrm{mL}$; both of these values were significantly higher than the corresponding values in group $\mathrm{S}$ (KL-6,750 U/mL and SP-A51.7 $\mathrm{ng} / \mathrm{mL}$, $\mathrm{p}=$ 0.038 and $\mathrm{p}=0.008$, respectively). The median durations of PFD therapy were 898 days in group L and 159 days in group $S(p<0.001)$. There were no other significant differences between groups $\mathrm{L}$ and $\mathrm{S}$ at the time of taking PFD.

Changes in the FVC are shown in Table 2. The median change per year before PFD therapy was $-300 \mathrm{~mL}$ in group $\mathrm{L}$ and $-390 \mathrm{~mL}$ in group $\mathrm{S}$. In group $\mathrm{L}$, the respective median changes in FVC were $-30 \mathrm{~mL},-120 \mathrm{~mL}$, and $-170 \mathrm{~mL}$ at the 6-, 12-, and 24-month time-points after taking PFD. The median change in the FVC at 12 months after taking PFD in group L $(-120 \mathrm{~mL})$ was significantly lower than that
Table 3. Adverse Events.

\begin{tabular}{lcccc}
\hline & Grade 1 & Grade 2 & Grade 3 & Grade 4 \\
\hline Photosensitivity & 3 & 0 & 0 & 0 \\
Anorexia & 4 & 4 & 0 & 0 \\
Nausea & 3 & 0 & 0 & 0 \\
Dyspepsia & 2 & 2 & 0 & 0 \\
Rash & 2 & 0 & 0 & 0 \\
$\gamma$-GTP elevation & 1 & 0 & 0 & 0 \\
ALT elevation & 2 & 0 & 0 & 0 \\
AST elevation & 3 & 0 & 0 & 0 \\
Hyponatremia & 0 & 0 & 1 & 0 \\
\hline
\end{tabular}

$\gamma$-GTP: $\gamma$-glutamyl transferase, ALT: alanine transaminase, AST: aspartate transaminase

at 12 months before taking PFD $(-300 \mathrm{~mL})(\mathrm{p}=0.025)$. In group $\mathrm{S}$, the median change in the FVC was $-30 \mathrm{~mL}$ at 6 months after taking PFD. Pulmonary function tests were rarely performed in group $\mathrm{S}$ after the six-month time-point.

The survival time from the commencement of taking PFD is shown in Fig. 1. The respective median survival times in groups $\mathrm{L}$ and $\mathrm{S}$ were 1,612 days and 285 days $(\mathrm{p}<0.001)$, and the respective 2-year survival rates were $86 \%$ and $18 \%$ $(\mathrm{p}<0.001)$. With regard to grade 3-5 AEs, only 1 patient was assessed as having grade 3 hyponatremia among all 46 patients investigated (Table 3).

We conducted a univariate analysis of the following 10 factors to identify those associated with being able to take PFD for over 1 year (group L): age over 70 years, male gender, smoker status, definite UIP pattern on HRCT, disease severity stage $4, \% \mathrm{FVC}<60 \%$, percentage diffusion capacity of the lung for carbon monoxide $\left(\% \mathrm{DL}_{\mathrm{co}}\right)<40 \%$, decline in FVC per year before taking PFD $>300 \mathrm{~mL}$, KL-6 $<1,000 \mathrm{U} / \mathrm{mL}$, and final PFD dosage $\leq 1,200 \mathrm{mg}$. A $\%$ FVC $<60 \%$ and KL-6 $<1,000 \mathrm{U} / \mathrm{mL}$ were found to be significant risk factors for being in group $S(p<0.05)$ in the univariate analysis and were therefore subjected to a multivariate analysis. As a result, a \%FVC $<60 \%$ was the only factor significantly associated with not being able to take PFD for over 1 year (odds ratio $0.240,95 \%$ confidence interval 
Table 4. Univariate and Multivariate Analyses.

\begin{tabular}{|c|c|c|c|c|c|c|c|c|}
\hline & \multirow{2}{*}{$\begin{array}{c}\text { Long group } \\
\mathrm{n}(\%)\end{array}$} & \multirow{2}{*}{$\begin{array}{c}\text { Short group } \\
\mathrm{n}(\%)\end{array}$} & \multicolumn{3}{|c|}{ Univariate analysis } & \multicolumn{3}{|c|}{ Multivariate analysis } \\
\hline & & & Odds ratio & $95 \% \mathrm{CI}$ & $\mathrm{p}$ value & Odds ratio & $95 \% \mathrm{CI}$ & $\mathrm{p}$ value \\
\hline Age $>70$ years & $13(43)$ & $10(63)$ & 0.600 & $0.174-2.073$ & 0.419 & - & - & - \\
\hline Male & $25(83)$ & $13(81)$ & 0.867 & $0.178-4.210$ & 0.859 & - & - & - \\
\hline Smoker & $27(90)$ & $11(69)$ & 4.091 & $0.831-20.138$ & 0.083 & & & \\
\hline Definite UIP & $23(77)$ & $14(88)$ & 1.826 & $0.730-19.314$ & 0.617 & - & - & - \\
\hline JRS severity 4 & $3(10)$ & $5(31)$ & 0.244 & $0.050-1.203$ & 0.083 & - & - & - \\
\hline$\% \mathrm{FVC}<60 \%$ & $5(17)$ & $9(56)$ & 0.194 & $0.051-0.737$ & 0.016 & 0.240 & $0.060-0.958$ & 0.043 \\
\hline$\% \mathrm{DL}_{\mathrm{CO}}<40 \%$ & $7(23)$ & $5(31)$ & 0.943 & $0.253-3.509$ & 0.930 & - & - & - \\
\hline$\Delta \mathrm{FVC}>300 \mathrm{~mL}^{*}$ & $9(30)$ & $6(38)$ & 0.965 & $0.275-3.386$ & 0.956 & - & - & - \\
\hline $\mathrm{KL}-6<1,000 \mathrm{U} / \mathrm{mL}$ & $8(27)$ & $10(63)$ & 0.257 & $0.072-0.923$ & 0.037 & 0.330 & $0.085-1.278$ & 0.109 \\
\hline $\mathrm{PFD}<1,200 \mathrm{mg}$ & $9(30)$ & $8(50)$ & 0.667 & $0.196-2.263$ & 0.516 & - & - & - \\
\hline
\end{tabular}

*Declines in forced vital capacity 12 months before taking PFD

CI: confidence interval, UIP: usual interstitial pneumonia, JRS: Japanese Respiratory Society, \%FVC: \% predicted forced vital capacity, \%DLCO: \% predicted diffusing capacity for carbon monoxide, $\Delta$ : changes in, FVC: forced vital capacity, KL-6: Krebs von den Lungen-6, PFD: pirfenidone

Table 5. Complications.

\begin{tabular}{llccc}
\hline & Long group $(\mathrm{n}=30)$ & Short group $(\mathrm{n}=16)$ & $\mathrm{p}$ value \\
\hline Acute exacerbation of IPF & $\begin{array}{l}\text { Total events } \\
\text { (number of patients) }\end{array}$ & 10 & 8 & N.S. \\
Pneumothorax & $(6)$ & 9 & 8 & \\
Total events & & $(7)$ & N.S. \\
(number of patients) & $(7)$ & 3 & 0 & N.S. \\
& $\begin{array}{l}\text { Total events } \\
\text { (number of patients) }\end{array}$ & $(3)$ & $(0)$ & \\
\hline
\end{tabular}

IPF: idiopathic pulmonary fibrosis, N.S.: not significant

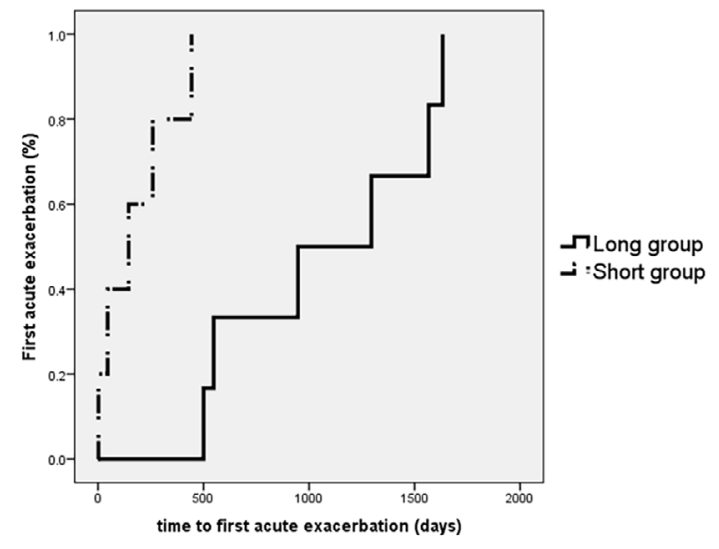

Figure 2. The time to the first acute exacerbation of idiopathic pulmonary fibrosis. The long-term pirfenidone group experienced a longer time free of the first acute exacerbation of idiopathic pulmonary fibrosis than the short-term pirfenidone group (947 days vs. 145 days, $p=0.001$ ).

\subsection{0-0.958, p=0.043) (Table 4).}

Finally, we analyzed the numbers of patients who developed acute exacerbation of IPF, pneumothorax, and lung cancer after taking PFD (Table 5). Although there were no significant differences in the numbers of patients who developed these conditions between groups $\mathrm{L}$ and $\mathrm{S}$, the patients in group L experienced a longer time free of acute exacerbation of IPF than those in group S (947 days vs. 145 days, p $=0.001)$ (Fig. 2).

\section{Discussion}

Thirty $(65 \%)$ of the 46 patients with IPF investigated in the current study were able to take PFD for over 1 year. The survival was better in group $\mathrm{L}$ than in group $\mathrm{S}$, and the 2year survival rate was $85 \%$. A $\% \mathrm{FVC}<60 \%$ seemed to be associated with not being able to take PFD for over 1 year. Patients in group L experienced a longer time free of the first acute exacerbation of IPF than those in group S, which was considered to result in a prolonged survival in the former group.

The efficacy and safety of PFD therapy in patients with IPF have been investigated in several clinical trials (2-4). In the "ASCEND" trial (2), which was a randomized controlled phase III trial reported in 2014, PFD exhibited superior efficacy to a placebo at 52 weeks after receiving PFD. There was a relative reduction of $47.9 \%$ in the proportion of patients who had an absolute decline of $\geq 10 \%$ in the $\% \mathrm{FVC}$ or who died in the PFD group. The baseline median \%FVC was $70 \%$ in the present study, which was almost the same as that reported in the ASCEND trial (67.8\%). 
With regard to the efficacy of PFD, the $-120 \mathrm{~mL}$ decline per year in group L in the current study was as good as the corresponding result in the ASCEND trial (2), which was $-235 \mathrm{~mL}$ in the PFD group. A study conducted in Japan (9) investigated the efficacy of PFD in 76 patients with IPF and showed a decline in the FVC of $-19 \mathrm{~mL}$ at 6 months after receiving PFD. This value is comparable to the corresponding result in the current study (a decline of $-30 \mathrm{~mL}$ ).

While there have been many studies on PFD therapy, only a few have investigated long-term PFD therapy. In a Japanese post-marketing surveillance study (5) including 1,371 patients with IPF and a median follow-up time of approximately 2 years, $48 \%$ of patients took PFD for over 1 year, and the median decline in vital capacity (VC) 1 year after receiving PFD was $4.7 \%$ (-100 $\mathrm{mL})$. Valeyre et al. (6) investigated the efficacy and safety of long-term PFD therapy. Their study included 789 patients with IPF from several clinical trials, including the CAPACITY (4) trial, and $37.1 \%$ of patients were able to take PFD for over 3 years and $22.2 \%$ for over 4 years (median 2.6 years). In the current study, $65 \%$ of patients with IPF were able to take PFD for over 1 year (median 898 days). Bando et al. reported on the efficacy of long-term PFD therapy, describing the clinical features and details of respiratory function tests in patients who were able to take PFD for over 2 years (longterm) (10). The FVC changes in the present study seemed to be worse at 12 months after taking PFD than those in the study of Bando et al. However, they were comparable at the 24-month time-point to those in the study of Bando et al. The difference in the definition of "long-term" may explain this discrepancy. In the current study, there were three patients who were unable to take PFD for more than 1 year not because of their poor clinical condition but because of side effects, and their median survival time was relatively short (498 days), suggesting that it is important to manage side effects and continue PFD therapy.

We performed a multivariate analysis in order to identify factors associated with being able to take PFD for over 1 year. As a result, $\% \mathrm{FVC}<60 \%$ was identified as a predictor of being in group $\mathrm{S}$. Tzouvelekis et al. investigated the safety and efficacy of PFD therapy in advanced IPF patients with severe lung function impairment (\%FVC $<50 \%$ and/or $\left.\% \mathrm{DL}_{\mathrm{co}}<35 \%\right)(11)$. In that study, PFD therapy was associated with a trend towards the amelioration of the functional decline compared to 6 months before treatment initiation but failed to show any benefit after 1 year of treatment ( $\Delta \%$ FVC: $-3.3 \%$ vs. $-0.49 \%$ vs. $-5.8 \%$ ). In the current study, there were 16 patients with advanced IPF who met this criterion. The efficacy of this therapy on the $\triangle \mathrm{FVC}$ seemed to be maintained in this study $(\Delta \% \mathrm{FVC}:-7.0 \%$ vs. $-2 \%$ vs. $-1.5 \%)$. However, there were only $8(50 \%)$ such patients in group L, and the median duration of PFD administration was only 298.5 days. These results suggest that PFD therapy should be initiated at an early stage in patients with IPF.

Costabel et al. reported the safety of long-term PFD therapy among over 1,000 IPF patients (7). However, the dosage of PFD and the patient characteristics differed from those in our study. There was only one patient who developed grade 3-5 adverse events in this study, indicating the universality of the safety of long-term PFD therapy in a real-world setting in Japan. In the analysis of the acute exacerbation of IPF, pneumothorax, and lung cancer, which are known to be major comorbidities associated with IPF, the patients in group L experienced a longer time free of acute exacerbation of IPF than those in group S. While the tyrosine-kinase inhibitor nintedanib may delay the time to the first acute exacerbation of IPF, whether or not PFD can reduce the rate of such acute exacerbation remains controversial (12). The results of the current study suggest the possibility of reducing acute exacerbations in patients with IPF via PFD therapy, which may be related to the better prognosis observed in group L. The longer time free of acute exacerbation of IPF in group L may also be attributed to differences in the baseline $\mathrm{FVC}$ and \% FVC between groups $\mathrm{L}$ and $\mathrm{S}$, as a low FVC is considered the most consistent risk factor for acute exacerbation of IPF (8).

The present study had several limitations. It was a retrospective study with a small sample size and conducted at a single center. In addition, the baseline FVC and \% FVC were better in group $\mathrm{L}$ than in group $\mathrm{S}$, which may have affected the results. We should carefully consider statistical biases when comparing values between groups $\mathrm{L}$ and $\mathrm{S}$.

\section{Conclusion}

A total of $65 \%$ of patients with IPF were able to take PFD for over 1 year. The efficacy and safety were satisfactory in these patients, and the time to the first AE of IPF was longer than in those who were unable to tolerate the long-term administration of PFD. A \%FVC $<60$ seems to be associated with not being able to take PFD for over 1 year.

The authors state that they have no Conflict of Interest (COI).

\section{References}

1. Raghu G, Collard HR, Egan JJ, et al. An official ATS/ERS/JRS/ ALAT statement: idiopathic pulmonary fibrosis: evidence-based guidelines for diagnosis and management. Am J Respir Crit Care Med 183: 788-824, 2011.

2. King TE Jr, Bradford WZ, Castro-Bernardini S, et al. A phase 3 trial of pirfenidone in patients with idiopathic pulmonary fibrosis. N Engl J Med 370: 2083-2092, 2014.

3. Taniguchi H, Ebina M, Kondoh Y, et al. Pirfenidone in idiopathic pulmonary fibrosis. Eur Respir J 35: 821-829, 2010.

4. Noble PW, Albera C, Bradford WZ, et al. Pirfenidone in patients with idiopathic pulmonary fibrosis (CAPACITY): two randomised trials. Lancet 377: 1760-1769, 2011.

5. Ogura T, Azuma A, Inoue $Y$, et al. All-case post-marketing surveillance of 1371 patients treated with pirfenidone for idiopathic pulmonary fibrosis. Respir Investig 53: 232-241, 2015.

6. Valeyre D, Albera C, Bradford WZ, et al. Comprehensive assessment of the long-term safety of pirfenidone in patients with idiopathic pulmonary fibrosis. Respirology 19: 740-747, 2014. 
7. Costabel U, Albera C, Lancaster LH, et al. An open-label study of the long-term safety of pirfenidone in patients with idiopathic pulmonary fibrosis (RECAP). Respiration 94: 408-415, 2017.

8. Collard HR, Ryerson CJ, Corte TJ, et al. Acute exacerbation of idiopathic pulmonary fibrosis. An international working group report. Am J Respir Crit Care Med 194: 265-275, 2016.

9. Okuda R, Hagiwara E, Baba T, et al. Safety and efficacy of pirfenidone in idiopathic pulmonary fibrosis in clinical practice. Respir Med 107: 1431-1437, 2013.

10. Bando M, Yamauchi H, Ogura T, et al. Clinical experience of the long-term use of pirfenidone for idiopathic pulmonary fibrosis. Intern Med 55: 443-448, 2016.
11. Tzouvelekis A, Ntolios $P$, Karampitsakos $T$, et al. Safety and efficacy of pirfenidone in severe Idiopathic Pulmonary Fibrosis: A real-world observational study. Pulm Pharmacol Ther 46: 48-53, 2017.

12. Costabel U, Inoue Y, Richeldi L, et al. Efficacy of nintedanib in idiopathic pulmonary fibrosis across pre-specified subgroups in INPULSIS. Am J Respir Crit Care Med 193: 178-185, 2016.

The Internal Medicine is an Open Access article distributed under the Creative Commons Attribution-NonCommercial-NoDerivatives 4.0 International License. To view the details of this license, please visit (https://creativecommons.org/licenses/ by-nc-nd/4.0/).

(C) 2018 The Japanese Society of Internal Medicine Intern Med 57: 2813-2818, 2018 